\title{
Contemporary outcomes of Rheumatic mitral valve surgery in the Mid-Atlantic region
}

\author{
Kanat Ozisik ${ }^{1}$ \\ ${ }^{1}$ Ministry of Health Ankara City Hospital
}

February 18, 2022

\begin{abstract}
Rheumatic mitral valve disease is now rare in high income countries, except for migrant and older residents, it remains an important and ongoing cause of preventable heart disease in Indigenous populations. Despite our major advances in medical technology and understanding, rheumatic fever remains a serious public health problem throughout the world.
\end{abstract}

\section{Hosted file}

comment.odt available at https://authorea.com/users/461221/articles/556970-contemporaryoutcomes-of-rheumatic-mitral-valve-surgery-in-the-mid-atlantic-region 